www.jmscr.igmpublication.org

Index Copernicus Value: 79.54

ISSN (e)-2347-176x ISSN (p) 2455-0450

crossrefDOI: https://dx.doi.org/10.18535/jmscr/v7i2.138

\title{
MTA AS A Root End Filling Material - An Invivo Study
}

\author{
Authors \\ Dr Elizabeth Prabha James ${ }^{1}$, Dr Ramesh Kumar $\mathbf{M}^{2}$, Dr Muhammed Abdul Rahman \\ $\mathrm{TV}^{3}$, Dr Dhanya Shaji ${ }^{4}$, Dr Mini Rajagopal ${ }^{5}$ \\ ${ }^{1}$ Associate Professor, Department of Conservative Dentistry and Endodontics, Govt. Dental College, \\ Kozhikode \\ ${ }^{2}$ Professor and Head, Department of Conservative Dentistry and Endodontics, KMCT Dental College, \\ Kozhikode \\ ${ }^{3}$ Senior Resident, Department of Conservative Dentistry and Endodontics, Govt. Dental College, Kozhikode \\ ${ }^{4}$ Assistant Professor, Department of conservative dentistry and endodontics, Govt. Dental College, Trissur \\ ${ }^{5}$ Lecturer, Department of Conservative Dentistry and Endodontics, Govt. Dental College, Kozhikode
}

\begin{abstract}
The aim of the study was to evaluate clinically and radiographically the periapical healing when MTA was used as a retrograde root end filling. Most endodontic failure occurs as a result of leakage of irritants from pathologically involved root canals. In cases where orthograde root canal cannot be done as in cases of open apex, or persistant periradicular infections, an endodontic surgery and retrograde filling is done. MTA was chosen as the root end material of choice as it helps in the growth of cement oblast like cells. Cementum deposition is essential for the regeneration of periodontal apparatus

Keywords: MTA, Periapical radiolucency, Root end filling, Pain, Swelling, Mobility.
\end{abstract}

\section{Introduction}

Most endodontic failures occur as a result of leakage of irritants from pathologically involved root canals. When nonsurgical attempts prove unsuccessful or are contraindicated, surgical endodontic therapy is needed to save the tooth. The root end filling material should provide an apical seal to an otherwise unobturated root canal or improve the seal of existing root canal filling material and be biocompatible with the periradicular tissues $^{1}$

The complexity of root canal systems, inadequate instrumentation and presence of physical barriers may necessitate surgical endodontic therapy in some cases. Once the root end preparation has been completed, a suitable root end filling material is inserted.

The reported success rate for endodontic surgery ranges from less than $50 \%$ to as high as $90 \% .14$. Although, a plethora of materials are available, no material has been found that fulfils all or most of the properties for an ideal root end filling material. Recently a new material MTA was developed by Mahmoud Torabinejad at Loma Linda University was used in this study .MTA has been claimed to seal off all the pathways between the root canal and the periradicular tissues. In addition, there is strong expression of the OCN gene after application of MTA, which helps in the growth of cementoblast like cells. ${ }^{3}$ Cementum deposition is essential for the 
regeneration of periodontal apparatus. The mean setting time was $2 \mathrm{hr}$ and $45 \mathrm{~min}$. Its compressive strength was $40+-4.4 \mathrm{MPa}$ and $67.3 \mathrm{MPa}$ after 21 days. ${ }^{1}$

Therefore, it would be of academic and clinical interest to evaluate the periapical healing when MTA was used as a retrograde root end filling, The present study was conducted in the department of Conservative Dentistry and Endodontics, Government Dental College, Calicut to evaluate the periapical healing when MTA was used as retro filling materials.

\section{Materials and Methods}

Patient Selection: Twenty patients with periapical lesions of anterior teeth were selected from the outpatient section of the Department of Conservative Dentistry and Endodontics, Govt, Dental College, Kozhikode to participate in this study

Inclusion Criteria: Patients between the age group of 15-35 years were selected. Patients were healthy and free of any systemic diseases. All the selected patients had periapical lesions in the maxillary anterior region. All the selected patients had at least one of the indications for periapical surgery like (1) Failed conventional root canal filling with pain and sinus tract (2) Periapical lesions of teeth with open apex which had a history of failed apexification (3) Roots affected with calcific degeneration and associated periapical lesions (4) Patients with brief period of time available for completion of therapy for teeth with periapical lesions..A complete periodontal examination was carried out and all were devoid of periodontal pockets. All the patients received one session of scaling to reduce gingival inflammation and minimize periodontal disease.

Exclusion criteria: Teeth with pathosis associated with vertical root fractures, teeth with coronal perforations, and teeth with periodontal bone loss detected with a periodontal probe (greater $>5 \mathrm{~mm}$ probing depth). ${ }^{9}$

\section{Radiographic Criteria}

Pre-operative radiograph of all selected cases showed well defined periapical radiolucency .The size of each periapical radiolucency were measured in millimeter both vertically and horizontally at maximum- extent of lesion. Only lesion with size greater than $10 \mathrm{~mm}$ in diameter in the radiograph were included in this study. Radiographic angulations were standardized for subsequent follow up during the period of study. Radiographs were taken by using film holder and paralleling technique. Standard angulations were used in each cases. Factors were kept at $8 \mathrm{~mA}$ and $60 \mathrm{kVp}$.

\section{Procedure Methodology}

Patient's data regarding age, sex, location of the lesion and associated signs and symptoms were recorded in the proforma. Complete surgical procedures were explained to the patient. After patient had signed the informed consent form each one was prepared for surgery. Routine blood and urine examinations were carried out. Thorough oral prophylaxis was done and oral hygiene instructions were given. Occlusal adjustments were made to remove interferences when necessary.

The root canals of involved teeth were prepared prior to surgery. In already filled teeth the existing gutta percha was removed and the canals were well prepared and cleansed with sodium hypochlorite and new root canal fillings were placed with guttapercha using lateral condensation method after taking working length. For all cases of wide open apices root canal fillings were done at the time of surgery.

All patients were advised to take an NSAID prior to surgical procedure in order to reduce post operative pain and swelling. Patients were advised to rinse with $0.2 \%$ chlorhexidine mouthwash prior to surgery to minimize the number of microbes in the mouth.

\section{Procedure}

Effective infection control procedures and barrier techniques were used. The surgical area were anaesthetized by infiltration anesthesia using $2 \%$ xylocaine with 1:80000 adrenalin. After isolating the area with gauze sponge, a rectangular flap was designed with two vertical and a sulcular incisions. The vertical incisions were put one tooth lateral to 
the involved teeth. The mucoperiosteal flap was then carefully elevated and reflected by using retractors.

In most of the cases, access to the root tip area was not required as a result of bony destruction. In other cases, the bony access to the root tip was prepared by cutting bone with a micromotor and a round bur at slow speed, using light brushing strokes, using light pressure and avoiding prolonged contact of the bur with the osseous surface. ${ }^{9}$ Proper water spray was also used to protect tissues from thermal injury. After obtaining suitable bony access, the periapical curettage was performed to remove the diseased tissues surrounding the root apex with sharp curettes. The curetted tissue was placed in $10 \%$ formalin solution for histopathological examination.

In teeth with open apex, the root canal was dried and obturated at this time. The excess filling material which extends beyond the apex were removed. The root apex was then resected with a high speed fissure bur with a slight labial bevel.. A standard cavity of $3 \mathrm{~mm}$ was then prepared at the resected root tip by using a small inverted cone bur. After drying the cavity, MTA was mixed with the distilled water supplied along with it, mixed as per the manufacturers instruction and placed into the cavity using a plastic amalgam carrier. Flap was repositioned and suturing was done.

\section{Post operative instructions and medications}

Patient was instructed to apply icepack with firm pressure to the face directly over the surgical site for 6-8hrs following surgery. (Alternatively 10 minutes on and 5minutes off. From the second post operative day onwards, they were instructed to rinse with antiseptic mouth wash (chlorhexidine $0.2 \%$ twice daily for 5 days following surgery).

\section{Medications given}

1. Amoxycillin $500 \mathrm{mg}$ tid for 5 days

2. Ibuprofen paracetamol combination 300mg and 200mg thrice daily for three days. Patient was advised to report after 3 days for suture removal.

\section{Follow up}

The patients were followed up for clinical and radiographic examination. Clinical parameters like pain on palpation, pain on percussion, mobility of the involved teeth, presence of draining sinus, swelling were evaluated at time intervals of 1 week, 3months, six months and nine months.

Pain on palpation was assessed by palpating with fingers on the buccal and palatal aspects of the mucosal tissue overlying the roots of the treated teeth.

Pain was graded as Mild, Moderate, and Severe and was scored as follows:

Score 0 - absence of pain

Score 1 - Mild pain

Score 2 - Moderate pain

Score 3 - Severe pain ie intolerable pain.

Pain on percussion was assessed, depending up on the degree of pain elicited on a light tap with the handle of a mouth mirror as follows:

Score -0 : absence of pain on percussion

Score -1 ; Mild

Score -2 : Moderate

Score - 3 : Severe

Mobility of involved teeth was assessed by using the blunt handles of two mouth mirrors and was scored as follows.

Grade 1: First distinguishable sign of mobility greater than normal.

Grade 2: Horizontal tooth movement no greater than $1 \mathrm{~mm}$.

Grade 3: Horizontal tooth movement greater than $1 \mathrm{~mm}$, with or without rotation or vertical depressibility.

Presence of draining sinus, swelling scored in the observation chart as (+) and (-) according to the presence or absence of the conditions respectively.

Radiographically, the presence of trabecular bone formation and size of the lesion were evaluated by a radiologist from oral medicine and radiology department who was not aware of the material used.. Patients were evaluated at time intervals of three months, six months, and nine months.. The radiographs were examined in a viewer with a magnifying glass. (to note the presence and absence of trabeculations.). The radiographs were digitalized and using the Adobe Photoshop, a grid of $1 \mathrm{~mm}^{2}$ was superimposed on the radiograph, to know the 
size of the lesion by recording the number of $\mathrm{mm}^{2}$ that showed evidence of involvement.

Scores used in radiographic findings:

0 - No radiographic changes as compared to the post surgical radiograph.

1 - Changes present. Radiographic evidence of trabeculae bone formation in less than $50 \%$ of the surgically created defect.

2 - Changes predominant . Radiographic evidence of trabecular bone in more than $50 \%$ of the surgically created defect.

3. - Normal. Normal radiographic appearance with normal periradicular osseous architecture and normal PDL space established at the resected root end.

By combining, the clinical and radiographic criteria, the success rate of periapical healing was evaluated in both groups. The criteria for healing classification as modified by Zetterquist et al (1991) and Jessslen (1995), were used to evaluate the rate of healing. The criteria is as follows: ${ }^{13}$

Success: the radiograph demonstrated complete healing of the former radiolucency and no clinical signs or symptoms were present.

Improvement: incomplete radiographic healing of atleast $50 \%$ and absence of any clinical signs and symptoms.

Failure: less than $50 \%$ radiographic healing or presence of clinical signs

\section{Observation and Results}

To evaluate healing ,clinically and radiographically, after periapical surgery using MTA as retrograde filling material, 20 patients were selected from outpatient section of Department of Conservative Dentistry and Endodontics, Govt. Dental College, Kozhikode.

\section{Clinical Evaluation}

Clinically the effectiveness of surgery were assessed by considering various signs and symptoms like pain on palpation and percussion, presence of draining sinus tract, mobility of involved teeth at time interval of one week, three months, six months, and nine months. One patient failed to report after three months. All data were tabulated and statistical analysis was performed using a chisquare test (SPSS). The level of significance was set at $\mathrm{p}<.05$.

Pain on palpation: it was observed that, preoperatively 5 patients of had mild pain on palpation. 3 patients had moderate pain on palpation. At one week 10 cases had mild pain. One case had mild pain at 3 months and from six months on wards, none of the cases had any pain on palpation.

On statistical evaluation, using the chi square test, ( df-1, P >0.05). it is inferred that pain on palpation was not statistically significant.. (Table I).

Pain on percussion, On evaluating it was observed that preoperatively 4 cases had mild pain on percussion whereas 6 cases of had moderate pain on percussion and 2 patients severe pain. At one week 8 cases had mild pain on percussion At three months, 1 patient had mild pain on percussion. From 6 months onwards none of the reported cases had any pain on percussion (Table 2)

On statistical analysis, it was found that (df $2: \mathrm{p}>$ .05 so pain on percussion was not significant statistically.

Disappearance of sinus tract On evaluation, it was found that preoperatively 5 cases had sinus tract preoperatively, At three months none of the cases reported sinus. On statistical analysis it was found that disappearance of sinus tracts was not statistically significant, since $\mathrm{p}>.05$. (Table 3 )

Swelling: Preoperatively 10 cases had swelling. At one week. 4 cases had swelling. From one month onwards none of the cases showed swelling involving the treated area. (Table 4)

On statistical analysis, using chisquare test (df 1 and $\mathrm{p}>$.05) Thus it is inferred that the disappearance of swelling, on healing was not statistically significant. Mobility: 6 cases grade 1 mobility preoperatively, and 4 cases of had grade II mobility. At one week and three months 10 cases had grade I mobility. After 6 months, 4 cases showed grade I mobility). On statistical analysis, mobility and periapical healing was found to be insignificant. (since $\mathrm{p}>$ $.05)$ 


\section{Radiographic evaluation}

Radiographically, size of the lesion in comparison to the preoperative radiograph and the presence of trabecular bone formation were evaluated. These evaluations were done at the time intervals of 3 months, 6 months, 9 months.

Trabecular bone: At 3 months, there was absence of trabeculae formation in two cases, trabeculae formation present in five cases and the rest of the cases showed predominant trabecular changes

At 6 months, 12 cases showed normal trabecular pattern (complete healing) and the six cases showed predominant trabecular changes and two cases showed trabecular changes in less than $50 \%$ of the defect

At 9 months, sixteen cases showed complete healing and four cases were in intermediate stage of healing, On statistical analysis ,the p value was .096 which is greater than .05 so it was inferred to be statistically insignificant.

Size of lesion: When the size of the lesion was evaluated at three months, all of the cases showed reduction in size, At six months and nine months respectively all the 10 cases showed marked reduction in size, On statistical analysis the $\mathrm{p}$ value was $>.05$ so inferred to be statistically insignificant. There were no statistically significant differences related to trabecular formation and reduction in size of the lesion, since $p>.05$. These results should be interpreted cautiously in view of the limited statistical power of study and should be considered as strictly pertinent to the observed sample and cannot be generalized.

\section{Success rate of healing}

In view of the above findings, according to Zetterqvist 's criteria, the overall success rate is $60 \%$ at 9 months.

\section{Result}

Table: 1 Pain On Palpation

\begin{tabular}{|l|c|c|c|c|}
\hline & Mild & Moderate & Severe & Absent \\
\hline $\begin{array}{l}\text { Pre } \\
\text { operatively }\end{array}$ & 5 & 3 & - & - \\
\hline 1 week & 10 & - & - & - \\
\hline 3 months & 1 & - & - & - \\
\hline 6 months & - & - & - & - \\
\hline
\end{tabular}

Table: 2 Pain On Percussion

\begin{tabular}{|l|c|c|c|c|}
\hline & Mild & Moderate & Severe & Absent \\
\hline Pre operatively & 4 & 6 & $\mathbf{2}$ & - \\
\hline 1 week & 8 & - & - & - \\
\hline 3 months & - & - & - & - \\
\hline 6 months & - & - & - & - \\
\hline
\end{tabular}

Table 3: Disappearance of Sinus Tract

\begin{tabular}{|c|c|c|c|c|c|}
\hline & Preoperative & $\begin{array}{c}1 \\
\text { Week }\end{array}$ & 3months & $\begin{array}{c}6 \\
\text { months }\end{array}$ & $\begin{array}{c}9 \\
\text { months }\end{array}$ \\
\hline Absent & - & - & - & - & - \\
\hline Present & 5 & 5 & - & - & - \\
\hline
\end{tabular}

Table 4: Swelling

\begin{tabular}{|l|c|c|c|c|c|}
\hline & Preop & 1Week & 3months & $\begin{array}{c}6 \\
\text { months }\end{array}$ & $\begin{array}{c}9 \\
\text { months }\end{array}$ \\
\hline Absent & - & - & - & - & - \\
\hline Present & 10 & 4 & - & - & - \\
\hline
\end{tabular}

Table 5 Mobility

\begin{tabular}{|l|c|c|c|c|c|}
\hline & Preop & $\begin{array}{c}1 \\
\text { Week }\end{array}$ & $\begin{array}{c}\mathbf{3} \\
\text { months }\end{array}$ & $\begin{array}{c}6 \\
\text { months }\end{array}$ & $\begin{array}{c}9 \\
\text { months }\end{array}$ \\
\hline Grade 1 & $\mathbf{6}$ & $\mathbf{1 0}$ & $\mathbf{1 0}$ & $\mathbf{4}$ & - \\
\hline Grade 2 & $\mathbf{4}$ & - & - & - & - \\
\hline Grade 3 & - & - & - & - & - \\
\hline
\end{tabular}

Table 6 Trabeculations

\begin{tabular}{|l|c|c|c|c|}
\hline & Preop & 3months & $\begin{array}{c}6 \\
\text { months }\end{array}$ & $\begin{array}{c}9 \\
\text { months }\end{array}$ \\
\hline Absent & 20 & 2 & - & - \\
\hline $\begin{array}{l}\text { Changes } \\
\text { present }\end{array}$ & - & 5 & 2 & - \\
\hline $\begin{array}{l}\text { Changes } \\
\text { predominant }\end{array}$ & - & 13 & 6 & 2 \\
\hline $\begin{array}{l}\text { Complete } \\
\text { Healing }\end{array}$ & & - & 12 & 18 \\
\hline
\end{tabular}

\section{Discussion}

Periapical surgery is done to remove pathologic tissue from the periapical region and simultaneously eliminate any source of irritation that could not be removed by orthograde root canal treatment ${ }^{11}$. Its outcome has been assessed in numerous studies with a reported success rate ranging from 41$94 \%$.The wide variation might be related to the differences in sample size, tooth types, indications for the operation, observation period, treatment procedures and materials used as well as criteria for success and recall rate. Factors that influence surgical intervention include quality of root canal filling, root canal anatomy and the presence of prosthetic restorations. ${ }^{11}$ 
The ultimate goal of periapical surgery is the predictable regeneration of periapical tissues including a complete repair of the osseous defects. After getting approval from the Human Ethical Committee Dental College, Kozhikode, this study was designed to evaluate the healing after periapical surgery, when MTA was used as retrograde filling materials, both clinically and radiographically. Case selection was done in accordance with swiah and walkers criteria.6. In all the cases of open apex obturation was done during surgery. In the failed nonsurgical case, it was retreated before surgery Tschamer Harnish et al stated better prognosis when the root filling was made before surgery. ${ }^{12}$

In this study, the size of the lesions were all greater than $10 \mathrm{~mm}$ at the maximum extent, which support the indication for surgery on the basis of the size of the lesion as suggested by Grossman et al whose guide lines suggest a lesion roughly 5 to $6 \mathrm{~mm}$ in diameter with an area of about 25 to $30 \mathrm{~mm}^{2}$. ${ }^{14}$

For adequate healing to occur there should be a fluid tight seal of the apical part of the root canal that is biologically compatible. Torabinejad M, Pittford TR et al in a bacterial leakage study with Staphylococcus epidermidis found that MTA prevented apical leakage of coronally introduced test bacterium. He also found that MTA induces hard tissue formation and the regeneration of new cementum over MTA is a unique phenomenon that has not been reported to occur with any other root end filling material. ${ }^{11}$ Radiographic examination of the periapical area is important for the evaluation of the periapical condition and for the success and failure of endodontic treatment. The most consistent radiographic feature aiding diagnosis of the periapical condition of the teeth is the density of trabeculae bone. ${ }^{8}$

In this present study, complete healing was observed in all the cases by about 9 months. How ever long term study with varieties of clinical cases and large sample size using this material is essential to conclude on its efficacy

\section{Summary}

In this study MTA ANGELUS was used as the retrograde root canal filling in the patients selected for surgery. All the patients showed complete healing in 9 months. It can be concluded that on the basis of a limited number of patients and relatively short observation period, the results of the present study showed a tendency towards a high success rate but a long term evaluation is needed to establish MTA as the material of choice in retrograde root end filling.

\section{References}

1. Don Schmitt et al. Multifaceted use of Proroot MTA. Pediatr Dent 23: 326 - 330, 2001

2. Edmund L Rapp: An anlysis of success and failure of apicoectomies.JOE . vol 17. No 10: oct 1991

3. Eng Tiong Koh et al . Cellular Response to Mineral Trioxide Aggregate. J OE, vol 24, No 8,1998

4. Israel Kaffe et al . Variations in the radiographic interpretation of the periapical dental region. Journal of endodontics, vol 14, No 7, 1988.

5. Itzhak Abramovitz et al . Case selection for apical surgery; A retrospective evaluation of associated factors and rational. JOE, 2002, vol $28,(7), 527-530$.

6. Itzhak Abramovitz. Case selection for apical surgery : A retrospective evaluation of associated factors and rational.JOE vol 28 , no 7, 2002

7. Jerome AH, Lindhe Boom et al. Comparative prospective randomized clinical study of MTA and IRM as root end filling materials in single rooted teeth in endodontic surgery. Triple O, Oct 2005; 100; 495-500.

8. John Danin et al . Clinical management of non healing periardicular pathosis. Oral surg, Oral med, Oral pathol, Oral radiol, Endod 1996; 82: 213-7. 
9. Silvio et al. Endodontic surgery with ultrasonic tips. One year follow up. September 2005; 100:380-387.

10. Silvio Taschieri et al. Endodontic surgery with ultrasonic tips : one year follow up. Oral surg, Oral med, Oral pathol, Oral radiol, endod 2005; 100: 380-7.

11. Tobon SI, et al. Comparison between a conventional technique and two bone regeneration techniques in periradicular surgery. International Endodontic Journal, 35, 635-641, 2002

12. Tschaner H,Das .Ergebnis der Nachkontrolle non 160 Warzelspitzenamputation en. Zahnarztl Kdsch 1967; 64: 432-436 in textbooks on endodontic surgery by Jorgen Rud, Andreasen and Molles Jensen.

13. Von Arx et al. Periradicular surgery of molars. International Endodontic Journal, 34,520-525,2001. 